bolism to $\mathrm{R} \Lambda$, and that synthesis of ddRA proceeds by dchydrogenation of retinol followed by sequential oxidations. ddRA is clearly a player of potential significance because its concentration in the limb bud is about six times greater than that of RA, so it will be important to determine if analysis of anterior and posterior fragments shows a difference in its level.

The chick limb bud assay has been used for some time to analyse other rcgions of the chick embryo for polarizing activity. and Hensen's node and the notochord are both able to evoke AP duplications". Wagner et $a l .{ }^{.}$now report that the floor plate. an epithelial structure at the ventral midline of the developing spinal cord, has polarizing activity. The floor plate may play a part in neural-tube dcvelopment, and in the formation of certain axonal projections ${ }^{12}$. Regions of developing neural tissuc lacking the lloor plate, including other regions of the spinal cord, have little or no activity, and the activity appears around the time of neural-tube closure before differentiation begins. So is it $\mathrm{RA}$ that is responsible?

As there is not enough tissue to analyse endogenous retinoids directly, the authors used metabolic labelling with tritiated retinol and analysed the production of RA and didchydroretinol. Both floor plate and neural tube without lloor plate produce these metabolites, but at a somewhat lower specific converting activity for the neural tube. There is thus some disparity between the polarizing-rcgion assays and the metabolic studies, and the authors suggest this may be resolved by the ability of the floor plate to accumulate retinol through the retinol-building protein. These questions remind us that the evidence that RA or ddRA are cndogenous morphogens in the limb bud is not yet compelling, and is even less so for the urodele blastema. For example, more evidence is needed to confirm that there are continuous variations in retinoid levels or in cellular responsiveness ${ }^{11}$, and that such variations actually determine the axial positions of cells.

The morphogenctic effects of RA on the limb produce structures that have normal morphology but that arise at an abnormal position on the developmental axis. It is not clear how widespread such effects will be, but they are distinct, at least in their consequences, from the traditional teratogenic effects of retinoic acid. A recent paper ${ }^{12}$ on induction of cleft palate in rodents illustrates that retinoids can act on diverse cell types and influence cell interactions.

At day 8 in the mouse embryo, cranial neural crest cells migrate to form the maxillary prominence from which the palatal shelves form. Exposure to RA at this stage affects both survival and migration of crest cells. Exposure of the palatal shelves from day 10 onwards has stage-

\section{The floods in eastern Australia}

MAJOR floods are a fact of life in inland eastern Australia. Those in April represented the eighth such event since 1950 . But they were also the most extensive on record, claiming five lives and causing hundreds of millions of dollars worth of damage to crops, livestock and farm equipment. The damage to some towns is so great that they may not survive in

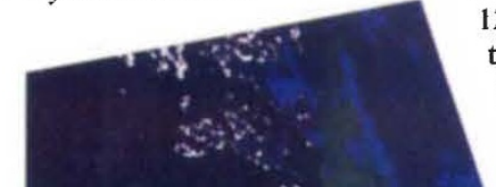
the long term. River levels in the region rose up to 12 metres above normal, and by 24 April more than $220,000 \mathrm{~km}^{2}$ of southern Queensland and northern New South Wales were submerged beneath a vast inland sea.

The picture is a satellite image of the floods of April 1990, produced from NOAAAVHRR satellite data collected on 24 April 1990. It shows the region from the tip of Cape York through western and central Queensland to western New South Wales. Red represents active river channels; yellow indicates standing water more than $1 \mathrm{~m}$ deep.

Inland eastern Australia lies within the catchments of three large drainage basins: the Darling to the east (largely draining the Eastern Highlands), and the Bulloo-Bancannia and Lake Eyre basins to the west (the latter fed largely by the Diamantina and Cooper Rivers). The susceptibility of this area to widespread flooding is a consequence of the unusual hydrological characteristics of these rivers. Their behaviour differs markedly from that of humid river systems. First, they show remarkable flow variability, with up to a thousand times more variation in mean annual discharge than in most European and North American rivers. Second, the active channel systems are able to expand to exceptional widths dur-

ing floods. Third, the flood discharge tends to decrease systematically downstream. Fourth, the flood pulses are of long duration, moving slowly down long, low-gradient channels.

Extremely high rainfall in the Eastern Highlands initiated the April floods. But this would normally have created only small-scale flooding, with the flood pulses decreas. ing downsteam through evaporation and infiltration into the underlying beds. On this occasion, however, the arrival of flows from the Highlands coincided with intense rainfall over central and western Queensland, as well as along the Eastern Highlands. New South Wales, meanwhile, having had drought conditions throughout the summer, also experienced intense rain that quickly saturated the ground surface and gave rise to high runoff.

Towns across the region were soon cut off, relying on emergency supplies brought in by air. When a second series of flood pulses arrived from the Eastern Highlands, many towns, such as Charleville on the Warrego River, had to be evacuated. In Charleville alone, the cost of the damage is estimated at over A\$100 million. But the full social and economic implications of the floods are yet to be assessed.

Stephen J. Gale and Scott Bainbridge

Stephen J. Gale is in the Department of Geography and Planning, University of New England, Armidale. New South Wales 2351, Australia. Scott Bainbridge is at Mapping and Monitoring Technology Pty Ltd, PO Box 5704 MC, Townsville, Queensland 4810, Australia. 